\title{
PEMODELAN PEMBANGKIT LISTRIK FOTOVOLTAIK YANG TERHUBUNG KE JARINGAN
}

\author{
Agus Yogianto ${ }^{1)}$, Ibnu Hajar ${ }^{2)}$, Septianissa Azzahra ${ }^{3)}$ \\ Teknik Elektro, Sekolah Tinggi Teknik-PLN \\ 12aayogi08@yahoo.com, ${ }^{2}$ ibnu.hjr@gmail.com, ${ }^{3}$ septianissa@sttpln.ac.id
}

\begin{abstract}
PLTS performances as a power plant does not only convert energy, so that electricity is generated, but in the study of power systems it becomes a major element that has an important role in the study of power systems. As a power system element, the PLTS acts as an element of electricity generation in this study modeled as a PV system and connected to the network, so it must meet the requirements of the electric power network operation. Through MATHLAB / SIMULINK modeling and simulation, a $100 \mathrm{~kW}$ peak PLTS power plant has been modeled connected to the network. From the simulation and analysis obtained, this PLTS model shows that the connected load affects the voltage condition but does not affect the frequency. The load power factor also affects the network, namely with a lower load power factor, it affects the voltage on the network.
\end{abstract}

Keywords: Photovoltaic, Modelling. Simulation, Grid

\begin{abstract}
ABSTRAK
Kinerja PLTS sebagai pembangkit listrik tidak hanya melakukan konversi energi, sehingga yang dihasilkan tenaga listrik, tetapi dalam studi sistem tenaga menjadi elemen utama yang mempunyai peran penting dalam studi sistem tenaga. Sebagai elemen sistem tenaga maka PLTS berperan sebagai elemen pembangkit listrik yang di dalam studi ini dimodelkan sebagai sistem PLTS dan dikoneksikan ke jaringan, sehingga harus memenuhi persyaratan operasi jaringan tenaga listrik. Melalui pemodelan dan simulasi MATHLAB/SIMULINK telah dimodelkan pembangkit listrik PLTS berkapasitas $100 \mathrm{~kW}$ peak yang terhubung ke jaringan. Dari simulasi dan analisa yang didapat, model PLTS ini menunjukkan bahwa beban yang terhubung mempengaruhi pada kondisi tegangan tetapi tidak mempengaruhi frekuensi. Faktor daya bebanpun berpengaruh pada jaringan, yaitu dengan faktor daya beban yang makin rendah, maka berpengaruh kepada tegangan pada jaringan.
\end{abstract}

Kata Kunci: Fotovoltaik, Pemodelan, simulasi, jaringan. 


\section{PENDAHULUAN}

Pembangkit listrik fotovoltaik (PV power plant) saat ini semakin berkembang penerapannya tidak hanya secara off grid tetapi juga dengan terhubung ke jaringan tenaga listrik. Operasi pembangkit listrik fotovoltaik yang terhubung ke jaringan semula baru pada kapasitas ratusan kilowatt pada sistem tenaga pulau kecil, tetapi sekarang sudah ada yang terhubung ke jaringan dengan kapasitas mencapai ribuan $\mathrm{kW}$. Semakin banyaknya pembangkit listrik fotovoltaik yang terhubung ke jaringan akan berpengaruh pada pengoperasian sistem tenaga listrik khususnya sistem distribusi tenaga listrik, karena pada umumnya pembangkit listrik fotovoltaik terhubung ke jaringan melalui tegangan rendah $380 \mathrm{~V}$ atau tegangan menengah $20 \mathrm{kV}$.

Studi sistem tenaga dengan koneksi pembangkit PLTS menjadi tidak memadai lagi, apabila diperlakukan hanya sebagai titik pada jaringan distribusi, tetapi dibutuhkan studi analisa yang lebih detail yaitu analisa sistem tenaga listrik.

Pada analisa sistem tenaga termasuk analisa kestabilan sistem tenaga selain diperlukan model pembangkit yang tepat, juga diperlukan parameter dari generator pembangkit yang lengkap. Pada penelitian ini model pembangkit yang dibuat belum dengan parameter sistem yang lengkap.

Pada penelitian ini yang dibuat adalah model pembangkit listrik fotovoltaik dengan tingkat iradians tetap, inverter dengan sistem kontrol tegangan dan filter untuk harmonisa tinggi, dengan menggunakan model bantuan MATLAB.

\section{METODOLOGI PENELITIAN}

\subsection{Panel Surya}

Panel surya pembangkit listrik tenaga surya tersusun dari modul-modul yang dirangkai seri untuk mendapatkan tegangan dc yang diperlukan bagi inverter. Susunan seri dari modul tersebut disebut sebagai string.

Jumlah modul dari string disesuaikan dengan tegangan minimal dan tegangan maksimum pada input inverter, agar pembangkit listrik dapat beroperasi secara andal dan kontinu.

Untuk mendapatkan kapasitas yang diperlukan, maka susunan string disusun paralel sehingga kemampuan arus dari pembangkit dapat memenuhi kapasitas yang ditentukan.

Elemen penyusun sebuah modul adalah sebuah sel surya. Sebuah sel surya yang menyusun sebuah modul adalah sebuah sumber arus yang besarnya tergantung kepada iradiasi yang menyinari modul tersebut. Semakin besar iradians surya, maka semakin daya yang dapat dihasilkan modul. Selain tergantung kepada iradians, juga tergantung kepada suhu pada modul, semakin tinggi suhu pada modul, maka semakin rendah daya yang dapat dihasilkan modul.

\subsection{Efek radiasi pada modul surya}

Kinerja pada modul surya sangat tergantung kepada iradiasi matahari, semakin tinggi iradiasi, maka arus yang dihasilkan sel surya akan semakin besar sehingga daya yang dihasilkan oleh modul surya juga semakin besar

\subsection{Efek suhu padamodul surya}

Sel surya akan beroperasi secara maksimum jika temperatur sel tetap normal (pada $25^{0} \mathrm{C}$ ), adanya kenaikan temperature yang lebih tinggi dari temperatur normal pada sel surya akan mengurangi tegangan sel surya. Setiap kenaikan temperature sel surya $1^{0}$ Celsius (dari $25^{\circ} \mathrm{C}$ ), maka akan mengurangi tegangan sekitar $0,4 \%$, sedangkan padadaya yang dihasilkan akan berkurang dua kali (2x) lipat untuk kenaikan temperature sel per $10^{\circ} \mathrm{C}$.

\subsection{Inverter sumber tegangan}

Pada pengoperasian inverter dikenal dua macam penggunaan inverter yaitu Inverter sumber tegangan (VSC/VSI voltage source converter/inverter) dan Inverter sumber arus (CSI Current source inverter). 
Sebagai sumber daya pembangkit listrik, maka yang digunakan adalah inverter sumber tegangan, karena sumber ini diharapkan mensuplai daya dengan tegangan konstan. Sebagai konverter sumber tegangan, dikenal perubahan daya dc ke daya ac dengan berbagai cara, yang pada dasarnya terkait dengan komutasi serta dengan switching tegangan.

Inverter yang umum dipakai saat ini digunakan inverter dengan modulasi lebar pulsa (Pulse Width Modulation) yang merupakan inverter dengan kerja yang diatur secara paksa atau regulated. Pada inverter ini tidak dipakai thyristor sebagai komponen utama inverter, tetapi dipakai komponen jenis transistor yang disebut IGBT (Insulated Gate Bypolar Transistor).

Tegangan searah yang masuk inverter dicacah dengan frekuensi tinggi serta bertingkat, tegangan sinusoidal diperoleh dari penjumlahan beberapa gelombang segiempat.

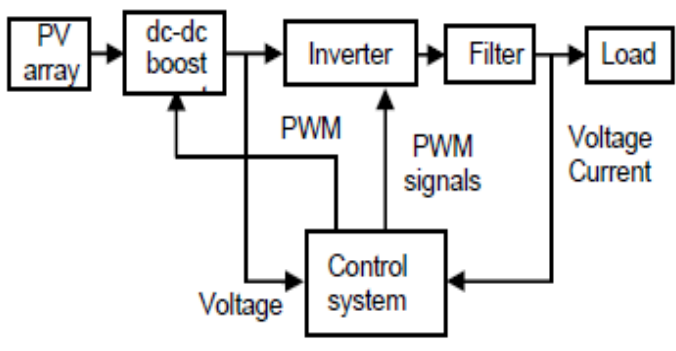

Gambar 1. Diagram blok inverter dengan modulasi lebar pulsa

Pada pemakaian inverter ada spesifikasi yang perlu diperhatikan yaitu meliputi:

- Tegangan input inverter

- Arus input inverter

- Tegangan output inverter

- Daya keluaran inverter

- Frekuensi keluaran

- Variasi tegangan keluaran

- Variasi frekuensi keluaran

- Efisiensi inverter

- Kemampuan regulasi / kontrol

- Kandungan harmonisa tegangan dan arus

\subsection{Jaringan tenaga listrik}

Jaringan tenaga listrik terdiri dari penghantar jaringan SUTT atau kabel dengan tegangan 20 $\mathrm{kV}$. Pada sistem $20 \mathrm{kV}$, jaringan tegangan menengah dapat berbentuk jaringan radial atau dapat berbentuk jaringan loop.

Pada umumnya beban yang disuplai oleh jaringan distribusi merupakan beban induktif. Pada konsumen beban induktif, operasi pada jaringan memerlukan persyaratan agar tidak terjadi jatuh tegangan yang melampaui batasan.

Pembangkit listrik yang terhubung pada sistem tenaga listrik diatur oleh ketentuan Grid Code, sedangkan yang terhubung pada sistem distribusi diatur oleh Distribution Code. Saat ini dengan perkembangan pembangkit energi terbarukan yang bervariasi outputnya, maka kebutuhan persyaratan bagi pembangkit listrik yang variatif masih perlu dilengkapi, terutama untuk menjaga kestabilan sistem.

Selain tegangan dan frekuensi yang harus memenuhi ketentuan jaringan, pembangkit listrik dengan perangkat konverter juga perlu memperhatikan kondisi Total Harmonic Distortion (THD).

Total Harmonic Distortion menyatakan kandungan harmonisa keseluruhan yang terdapat pada tegangan yaitu :

$$
\mathrm{THD}=\mathrm{V} \Sigma \mathrm{Vi}^{2} / \mathrm{Vbx} 100 \%
$$

dengan :

$\mathrm{Vi}=$ magnitude tegangan harmonisa ke $\mathrm{i}, \mathrm{i}=2 \mathrm{dst}$

$\mathrm{Vb}=$ tegangan pada frekuensi dasar 
Menurut SPLN tentang harmonisa, ditentukan THD tegangan yang diijinkan sebesar 5\%.

\subsection{Pembuatan model}

Sebelum simulasi dilakukan langkah awal adalah membuat model yang terdiri dari model panel surya, model inverter yang lengkap beserta sistem kontrol serta model jaringan. Berdasarkan spesifikasi masing-masing kapasitas maka dapat dibuat model pembangkit listrik sebagai berikut:

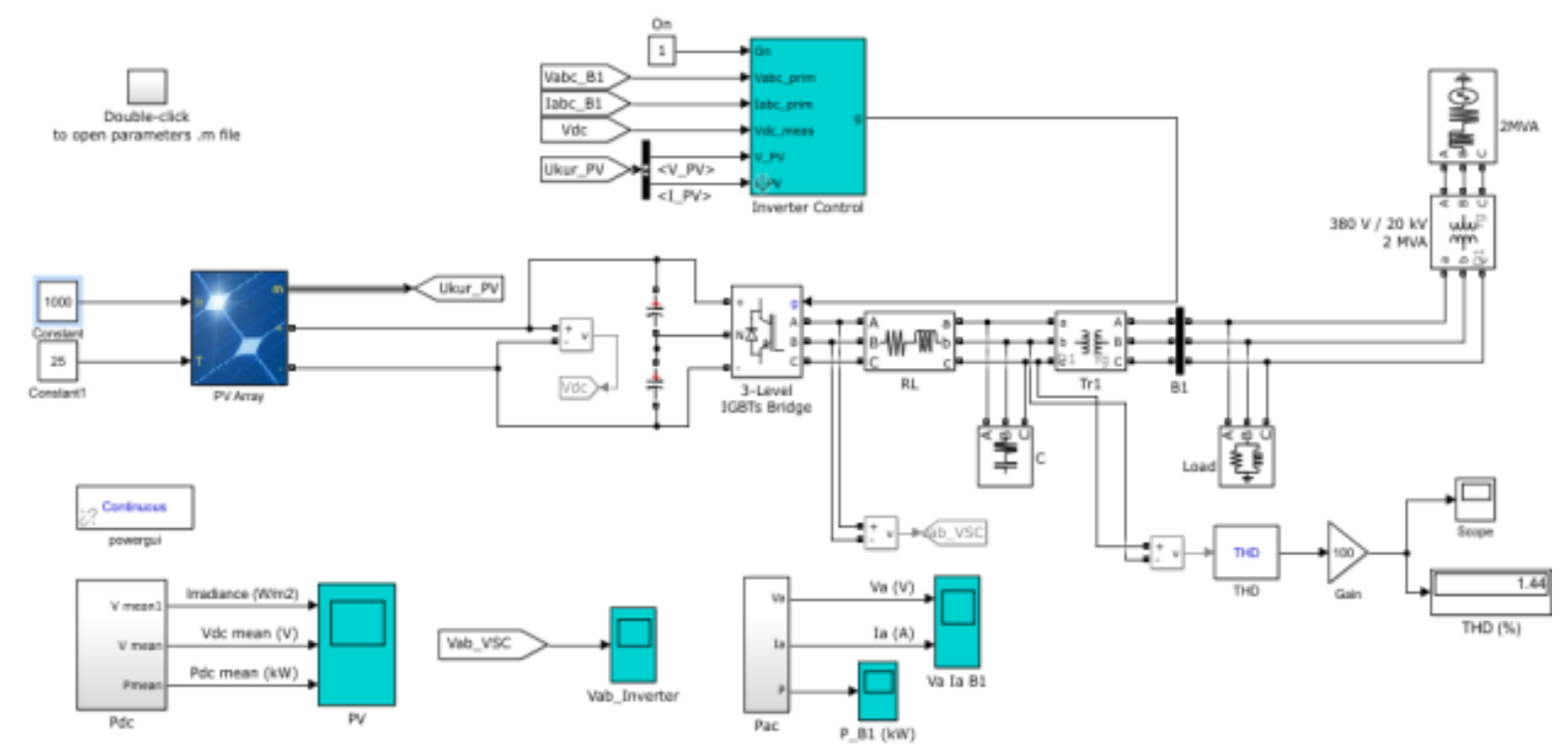

Gambar 2. Model Pembangkit Listrik Fotovoltaik Terhubung Ke Jaringan

\subsection{Prosedur Pengambilan Data}

Setelah diperoleh model, maka model tersebut dirun atau dilakukan simulasi. Pertama-tama dilakukan pemeriksaan model panel surya dengan melihat keluaran daya yang dihasilkan pada mode iradiasi tetap dengan suhu diubah pada dua harga, selanjutnya dilihat keluaran daya pada suhu tetap dengan iradians diubah.

Langkah selanjutnya setelah memastikan bahwa panel surya berjalan sesuai dengan rencana, maka dilakukan pemeriksaan terhadap kerja inverter sebelum dan sesudah filter pelalu frekuensi rendah.

Setelah dipastikan bahwa keluaran tegangan inverter sebelum dan sesudah keluaran filter sesuai dengan yang direncanakan, maka dilakukan simulasi operasi paralel dan pembebanan pada pembangkit listrik tenaga surya. Beban pada jaringan pada umumnya adalah beban induktif, oleh sebab itu dilakukan pembebanan induktif secara bertahap dan dilihat kondisi jaringan pada kapasitas tertentu.

Apabila kondisi jaringan terutama pada kondisi tegangan sudah melampaui batas terlalu rendah, maka dilakukan peningkatan kapasitas jaringan.

\section{HASIL DAN PEMBAHASAN}

\subsection{Pengujian Model}

Pengujian model dilakukan bertahap mulai dari pengujian panel surya, pengujian keluaran inverter dan pengujian pada jaringan dengan pembebanan.

Pada pengujian panel dengan iradians tetap $1000 \mathrm{~W} / \mathrm{m}^{2}$ dan suhu modul $25^{\circ} \mathrm{C}$, diperoleh kapasitas panel surya sesuai dengan rancangan seperti pada gambar berikut 


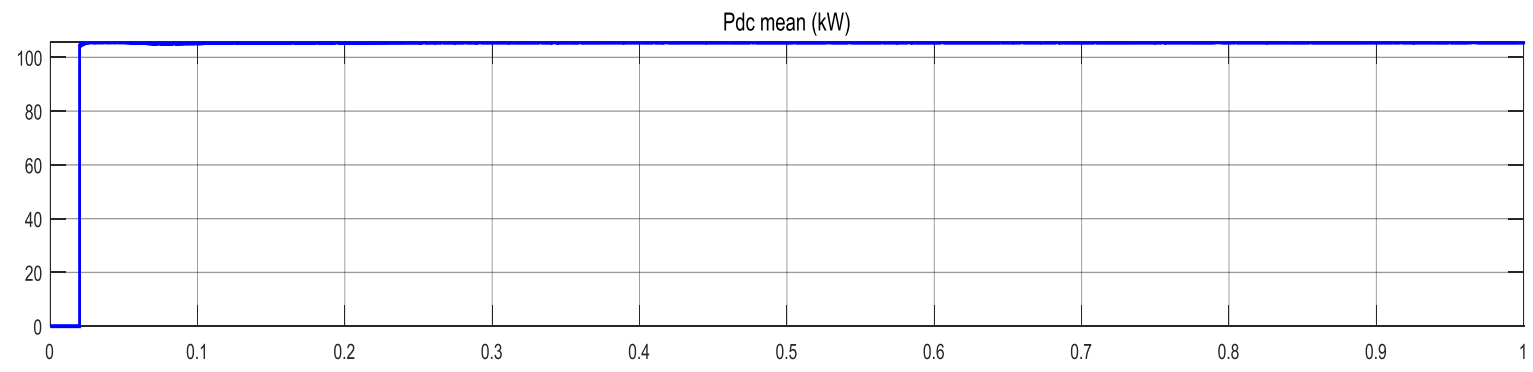

Gambar 3. Daya keluaran panel surya pada iradians $1000 \mathrm{~W} / \mathrm{m} 2$

Pada keluaran inverter sebelum filter diperoleh tegangan bolak-balik dengan bentuk segiempat yang tercacah sebagai hasil dari penjumlahan gembang persegi, seperti terlihat pada gambar berikut:

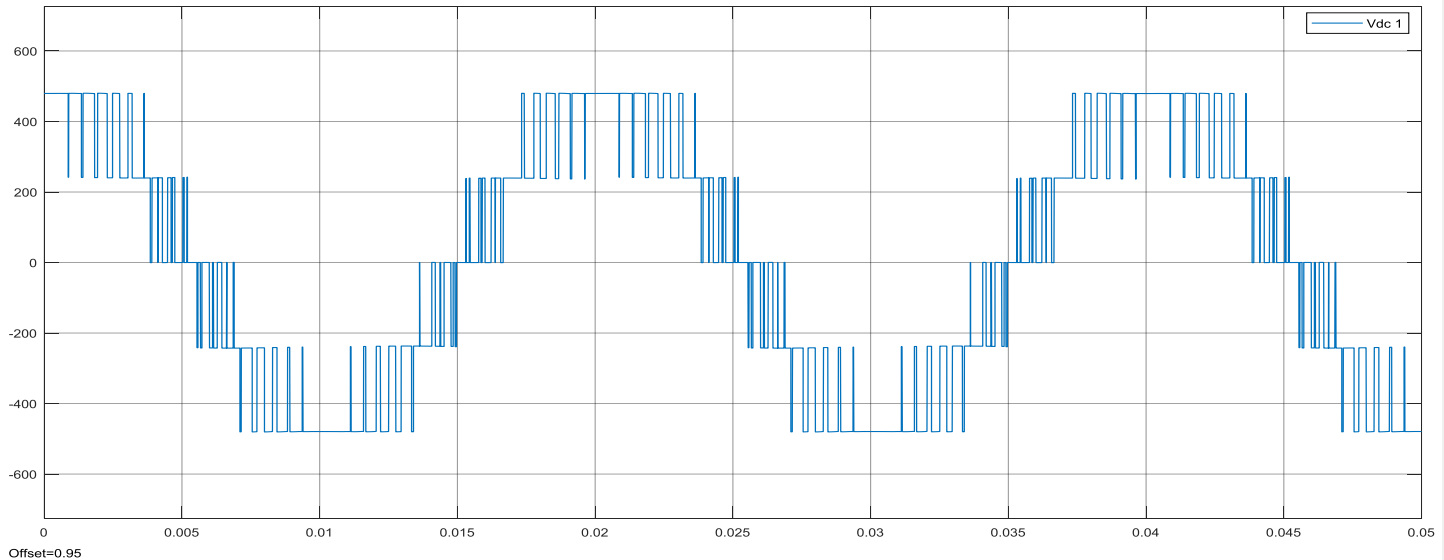

Gambar 4. Tegangan keluaran inverter

Selanjutnya dengan operasi terhubung ke jaringan, dilakukan pembebanan pembangkit liistrik fotovoltaik ini secara bertahap mulai dari 5, kVAR, $10 \mathrm{kVAR}$ sampai dengan $20 \mathrm{kVAR}$ dan diperoleh tegangan pada jaringan dan THD sebagai berikut:

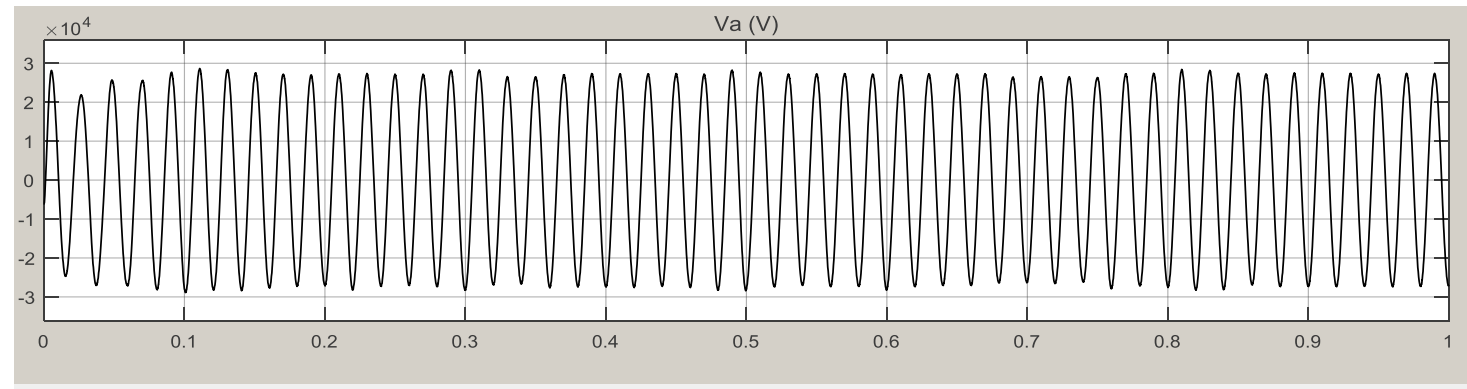

Gambar 5. Tegangan jaringan $20 \mathrm{kV}$ dengan beban induktif $5 \mathrm{KVAR}$

Dari monitoring tegangan jaringan, dapat diketahui bahwa frekuensi jaringan sekitar $50 \mathrm{~Hz}$ dengan besar tegangan antar fasa 19,2 kV, dengan demikian masih memenuhi ketentuan jaringan pada tegangan menengah. 


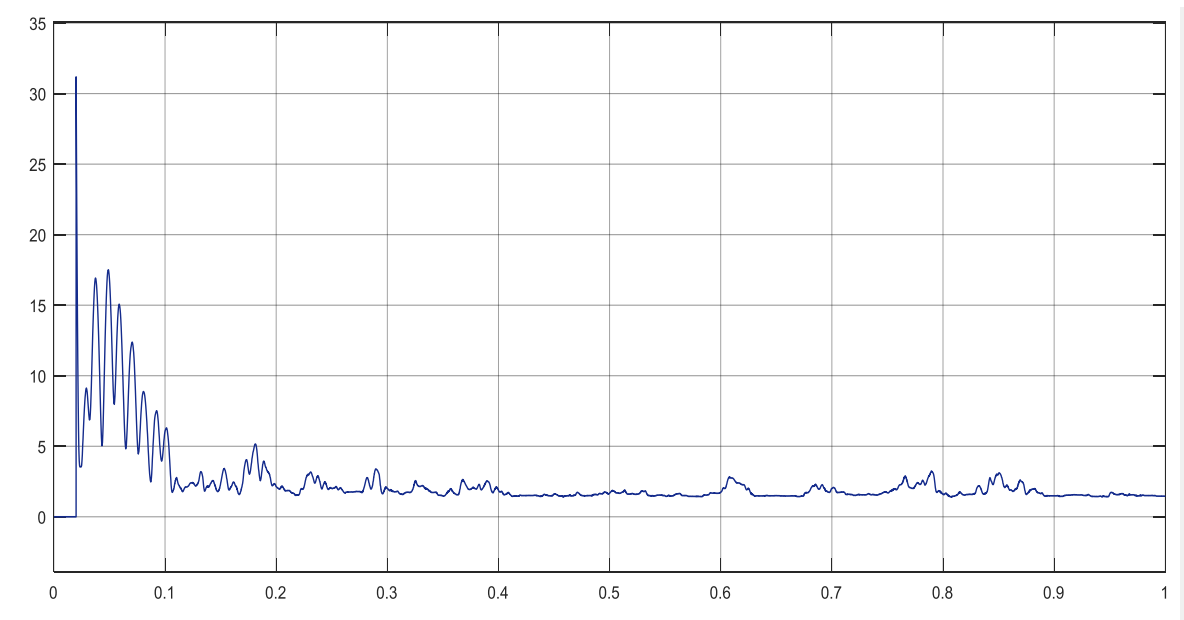

Gambar 6. THD tegangan pada beban induktif $5 \mathrm{kVAR}$

Dari monitoring tegangan dengan melalui perekam harmonisa dapat diketahui pada beban resistif $90 \mathrm{~kW}$ dan induktif $5 \mathrm{kVAR}$, diperoleh THD pada kondisi steady state sebesar 1,41\%. Hal ini menunjukkan bahwa pengoperasian pembangkit surya dengan inverter ini, masih memenuhi batasan harmonisa yang ditentukan oleh jaringan listrik, yaitu dengan batasan maksimum THD 5 $\%$.

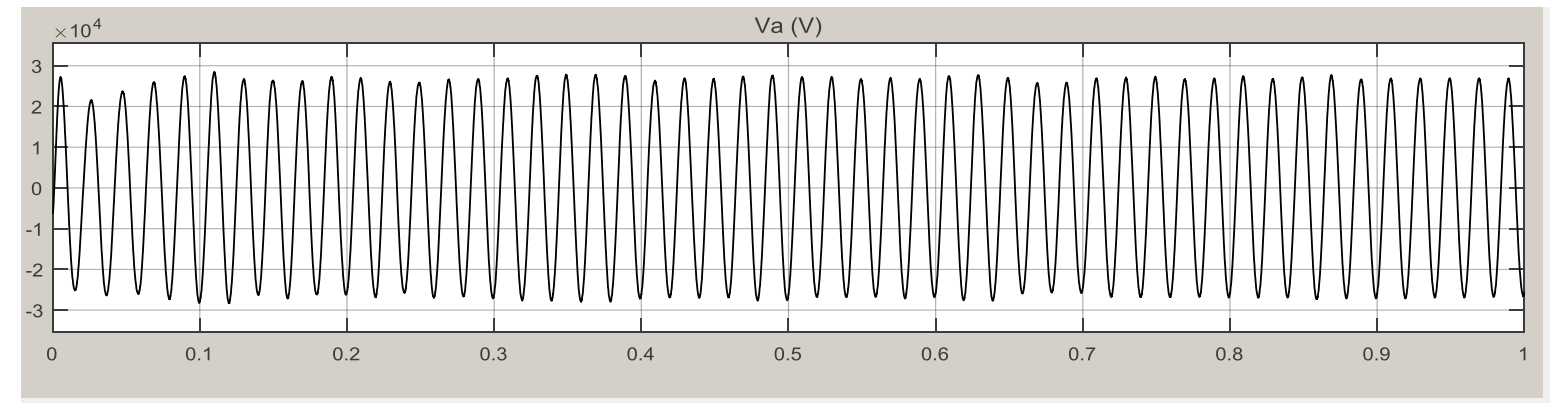

Gambar 7. Tegangan jaringan $20 \mathrm{kV}$ dengan beban induktif $10 \mathrm{kVAR}$

Dari monitoring tegangan jaringan, dapat diketahui bahwa frekuensi jaringan sekitar $50 \mathrm{~Hz}$ dengan besar tegangan antar fasa $18,9 \mathrm{kV}$, dengan demikian masih memenuhi ketentuan jaringan pada tegangan menengah

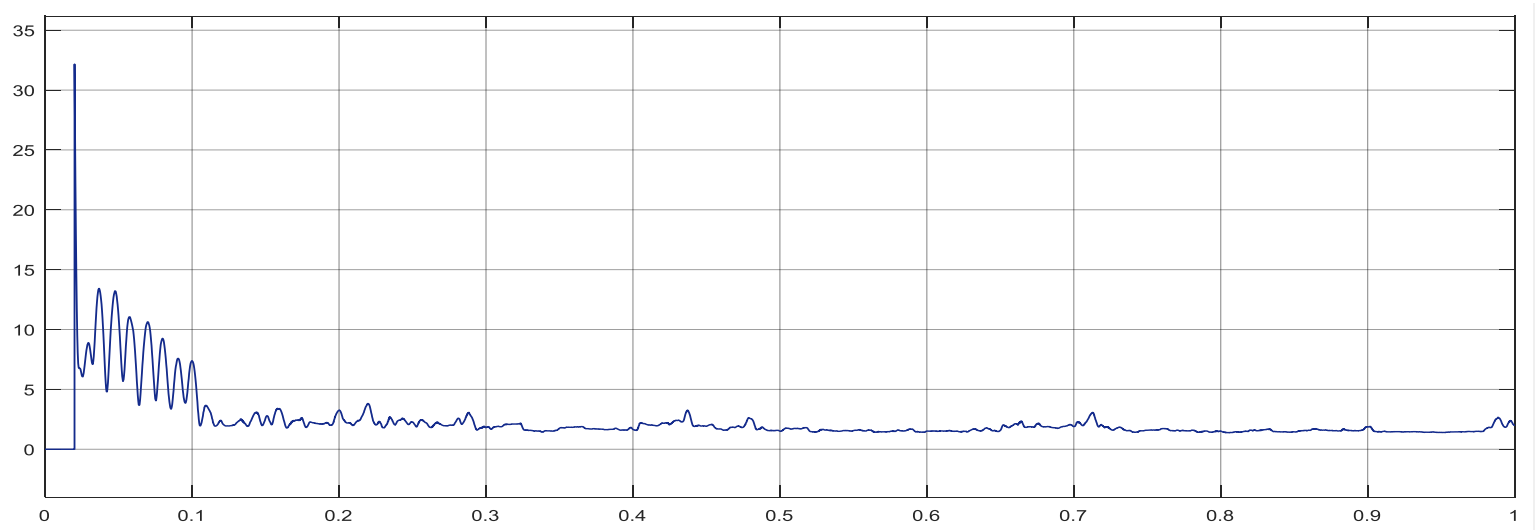

Gambar 8. THD tegangan pada beban induktif $10 \mathrm{kVar}$ di sisi $20 \mathrm{kV}$ 
Monitoring terhadap THD disisi output trafo dengan beban induktif lebih besar yaitu 10 kVAR relatif tidak terlalu besar menambah besarnya harmonisa, hal ini ditunjukkan dengan nilai THD yang menjadi $1,96 \%$. Dengan nilai THD ini, operasi pembangkit listrik fotovoltaik, masih memenuhi ketentuan jaringan.

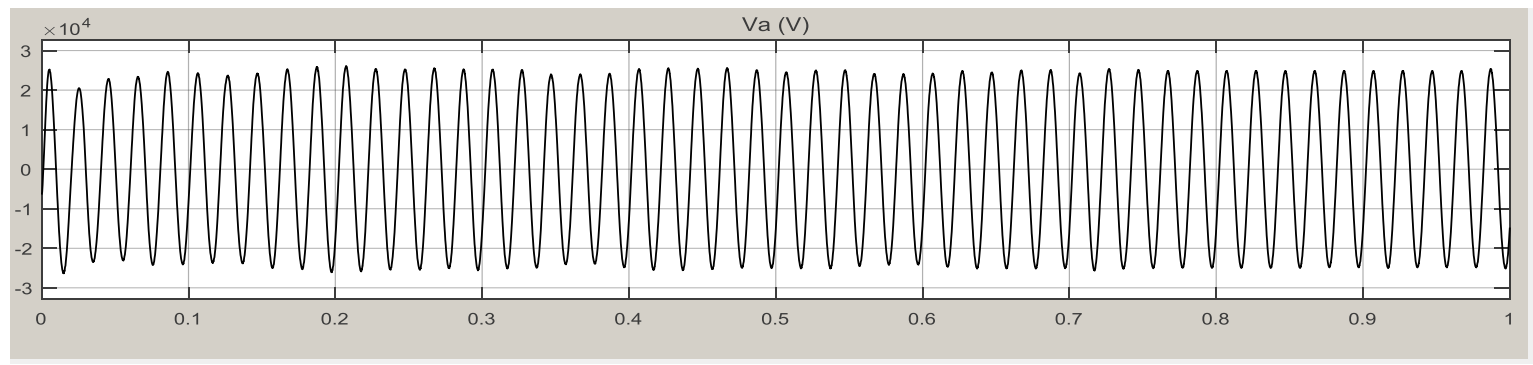

Gambar 9. Tegangan di jaringan $20 \mathrm{kV}$ pada beban induktif $20 \mathrm{kVAR}$

Dari hasil simulasi dapat diketahui bahwa sekalipun frekuensi jaringan sekitar $50 \mathrm{~Hz}$, besar tegangan antar fasa menjadi sebesar $17,5 \mathrm{kV}$. Dengan tegangan antar fasa sebesar nilai ini, yang melebihi batasan - $10 \%(18 \mathrm{kV})$, maka pengoperasian dengan beban $90 \mathrm{~kW}$ dan beban induktif 20 kVAR tidak diijinkan, kecuali ada penggunaan kapasitor atau kapasitas dari sistem lebih besar dari 2 MVA.

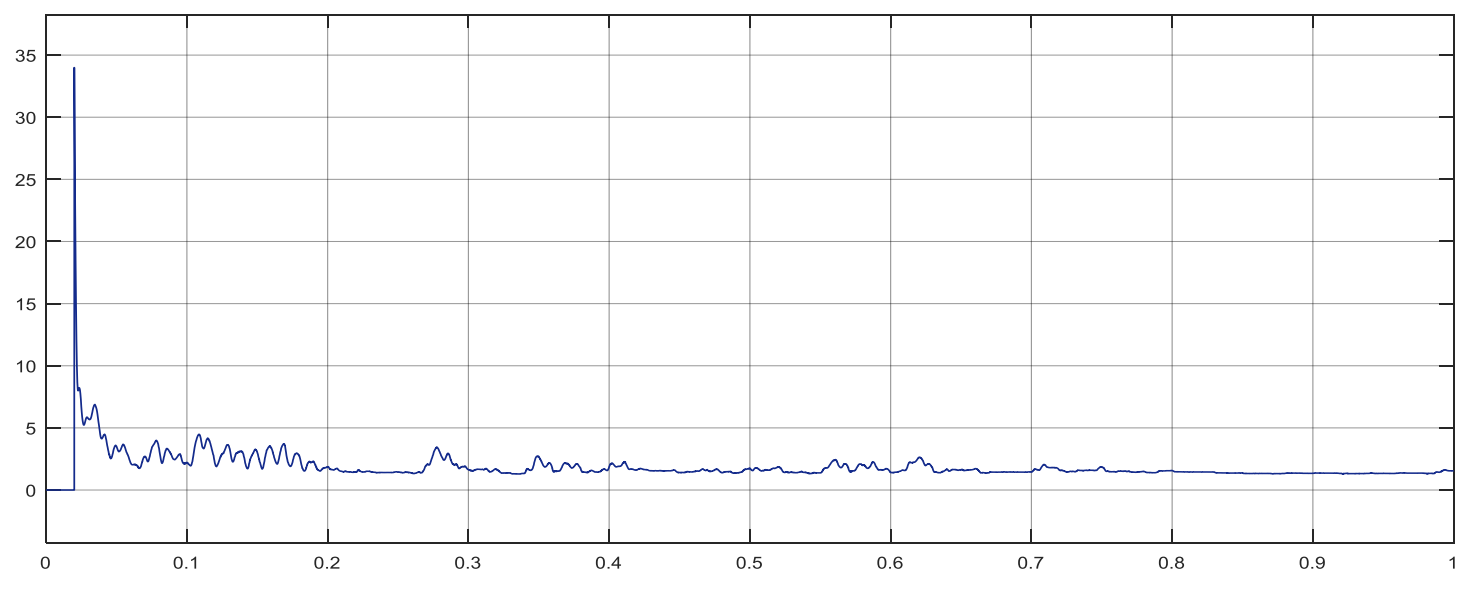

Gambar 10. THD tegangan pada beban induktif $20 \mathrm{kVAR}$ di sisi $20 \mathrm{kV}$

Monitoring terhadap THD tegangan di sisi $20 \mathrm{kV}$ menunjukkan bahwa nilai THD tetap dalam batas yang dipersyaratkan $(<5 \%)$ yaitu sekitar $1,55 \%$.

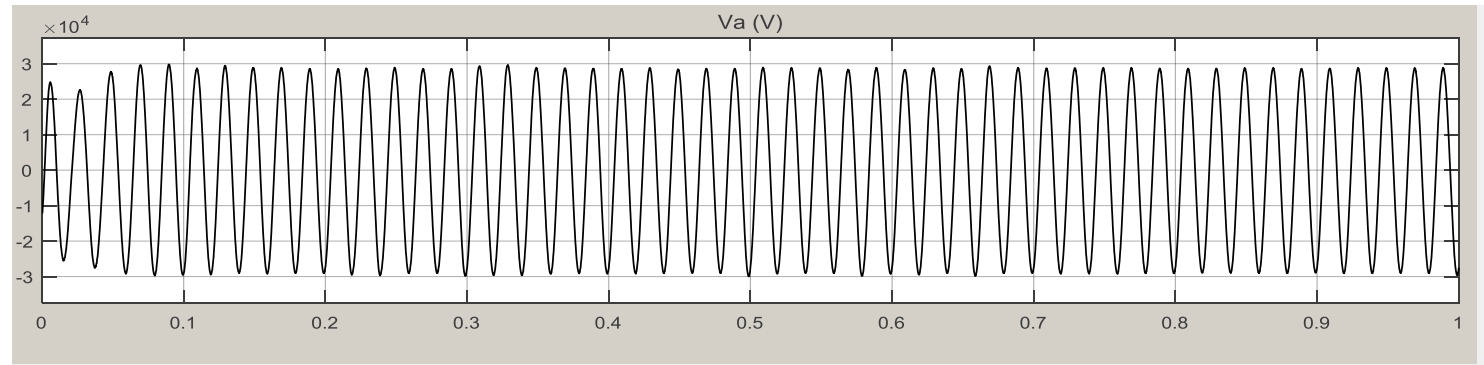

Gambar 11. Tegangan di jaringan $20 \mathrm{kV}$, 4MVA, beban induktif $20 \mathrm{KVAR}$ 
Dari monitoring tegangan jaringan, dapat diketahui bahwa frekuensi jaringan sekitar $50 \mathrm{~Hz}$ dengan besar tegangan antar fasa $20,3 \mathrm{kV}$, dengan demikian memenuhi ketentuan jaringan pada tegangan menengah. Sekalipun beban induktif cukup besar $20 \mathrm{kVAR}$, beban ini mampu dilayani dengan sistem berkapasitas 4 MVA.

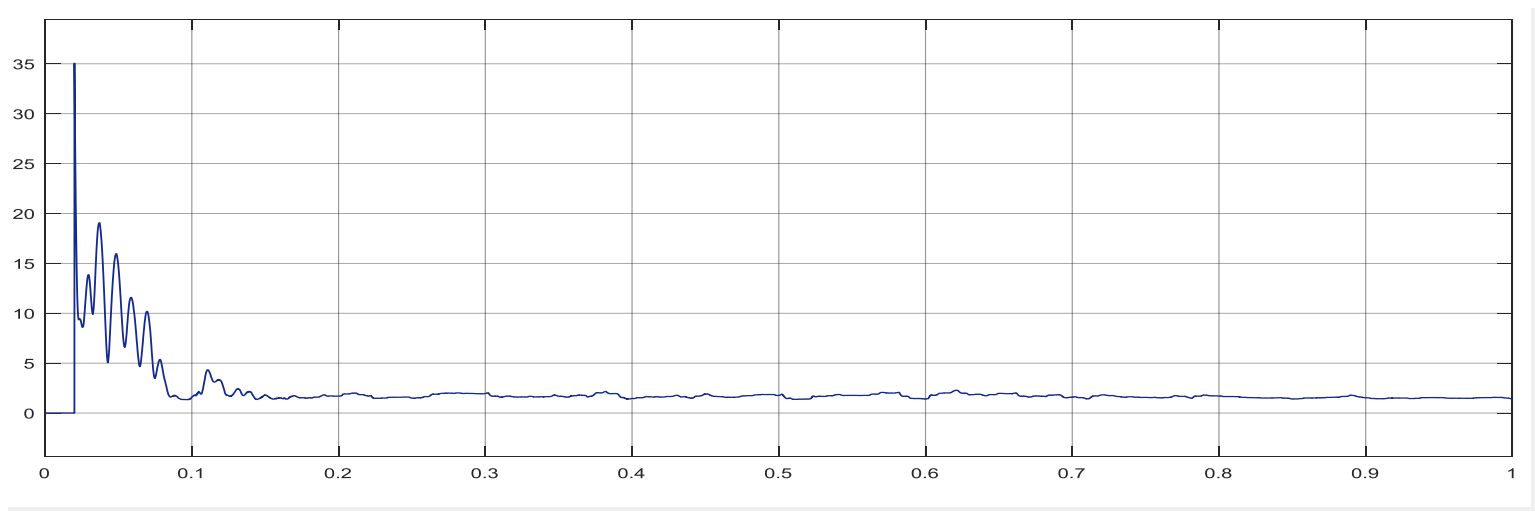

Gambar 12. THD tegangan pada beban induktif $20 \mathrm{kVAR}$, sistem 4 MVA

Dari hasil monitor THD, diketahui bahwa THD tegangan pada kondisi steady state tidak lebih dari $1,45 \%$. Hal ini menunjukkan bahwa operasi pembangkit listrik tenaga surya fotovoltaik ini, dapat memenuhi persyaratan THD untuk jaringan.

\section{Kesimpulan}

Dari pemodelan dan simulasi pembangkit fotovoltaik kapasitas $100 \mathrm{~kW}$ yang terhubung ke jaringan,maka dapat disimpulkan sebagai berikut :

1. Model panel surya dapat memenuhi spesifikasi yang ditentukan yaitu dengan keluaran tegangan $485 \mathrm{~V}-500 \mathrm{Vdc}$ serta daya keluaran $100 \mathrm{~kW}$ pada iradians $1000 \mathrm{~W} / \mathrm{m}^{2}$ dan suhu modul $25^{\circ} \mathrm{C}$.

2. Model inverter yang disusun dapat memenuhi spesifikasi jaringan yaitu dengan tegangan keluaran antar fasa $380 \mathrm{~V}$, frekuensi $50 \mathrm{~Hz}$ dan keluar dari trafo $380 / 20 \mathrm{kV}$ menjadi tegangan antar fasa $20 \mathrm{kV}$.

3. Model pembangkit tenaga surya fotovoltaik yang terhubung ke jaringan yang dirancang, dapat memenuhi kebutuhan beban resistif dengan tegangan, frekuensi dan THD yang memenuhi batasan pada ketentuan penyambungan ke jaringan tenaga listrik PLN.

4. Model pembangkit tenaga surya fotovoltaik ini dapat memenuhi kebutuhan beban induktif secara terbatas, pada kapasitas sistem 2 MVA, sampai dengan beban $90 \mathrm{~kW}, 10 \mathrm{KVAR}$ atau dengan faktor daya 0,99 .

5. Model pembangkit tenaga surya fotovoltaik ini dapat dibebani dengan beban induktif yang lebih besar dengan peningkatan kapasitas sistem, pada sistem 4 MVA, beban dapat mencapai $90 \mathrm{~kW}, 20 \mathrm{kVAR}$ atau faktor daya $0,976$.

\section{DAFTAR PUSTAKA}

[1] Ali Keyhani, M Marwali, Min Dai, Integration of Green and Renewable Energy in Electric Power System, Wiley and Son, Inc, 2010

[2] Bogdan Gorgan dkk, 2015. PV Plant Modelling for Power System integration using PSCAD Software, University of Polytechnica of Bucharest

[3] Gfritz Schimpf, Lars E Norum, Grid connected Converters for Photovoltaic, state of the art, Ideas for Improvement of transformerless inverters, Norwegian University of Science and technology, NTNU, Norway,2008 
[4] IEEE 1547.1.2015,Standard Conformance Test Procedures for equipment interconnecting Distributed resources with electric power systems.

[5] Mahrous Ahmed, three phase three level voltage source inverter with three phase two level as main circuit, Faculty of Engineering University of Egypt

[6] N Chayawatto dkk. 2015. Distributed Generation: Study on Converter Modelling on PV grid connected system under islanding phenomena. Clean Energy System, Thailand

[7] PTPLN(Persero), Pedoman Penyambungan Pembangkit Listrik Energi Terbarukan ke sistem distribusi PLN, Keputusan Direksi PLN, Juli 2014

[8] PT PLN(Persero), SPLN D5.004-1 : 2012, Power Quality (Regulasi harmonisa, Flicker dan ketidakseimbangan tegangan), 2012 


\section{FORMAT PENULISAN JURNAL ILMIAH KILAT}

\section{PANDUAN UNTUK PENULIS}

KILAT adalah jurnal ilmiah yang diterbitkan oleh STT-PLN. Jurnal Kilat diterbitkan dua kali dalam satu tahun pada bulan April dan Oktober dan berisi hasil penelitian, kajian dan analisis di bidang Teknologi, seperti bidang Teknik Mesin, Teknik Elektro, Teknik Sipil dan Teknik Informatika, Hukum dan Ekonomi yang terkait dengan kajian di bidang Energi Baru Terbarukan, Konversi Energi, Ketenagalistrikan, Telekomunikasi, Sistem Kontrol/Kendali, Elektronika dan Instrumentasi, Material dan Konstruksi, Project Management, Sistem Transportasi, Supply Chain Management, Arsitektur, Sistem Komputer dan Sistem Informasi. Jurnal Kilat diharapkan dapat menjadi referensi yang up to date bagi pengembangan, penelitian dan kajian di bidang tersebut.

\section{ATURAN REDAKSI UNTUK PENULIS}

\section{Kepengarangan (Authorship)}

Setiap penulis yang mengirimkan Naskah ke tim redaksi harus mematuhi beberapa kriteria sederhana yang telah ditetapkan oleh tim redaksi, yakni:

- Bersedia dan berkontribusi dalam melakukan perbaikan atas kelengkapan data jika masih ditemui kekurangan maupun kesalahan.

- Berkontribusi dalam memberikan penjelasan yang jelas dari isi naskah baik referensi, data yang diberikan, analisis dan sintesis.

- Penulis harus bersedia untuk menerima hasil evaluasi dari mitra bestari dan melakukan perbaikan naskah sesuai dengan waktu yang telah diberikan oleh tim redaksi.

- Menyetujui naskah untuk diterbitkan apabila sudah diresmikan oleh tim redaksi.

2. Orisinalitas dan Duplikat Publikasi

KILAT hanya akan memuat tulisan asli yang belum pernah diterbitkan atau dipublikasikan pada jurnal secara nasional maupun internasional (penulis wajib Surat Pernyataan Keaslian Naskah).

3. Naskah yang dikirim untuk dipublikasikan di KILAT juga merupakan persetujuan dari seluruh penulis Naskah tersebut. Naskah yang telah lulus seleksi akan dipublikasikan di dalam Jurnal IImiah KILAT atas nama penulis yang terkait. 


\section{FORMAT JURNAL}

A. Judul. Penamaan judul hendaknya dibuat seringkas mungkin, dan mencerminkan isi naskah secara keseluruhan. Times New Roman, Font size 14.

B. Data Penulis Tuliskan nama para penulis (nama lengkap tanpa gelar atau jabatan lainnya), Fakultas/Departemen, dan Universitas/Institusinya. Times New Roman, Font size 11.

C. Abstrak. Abstrak ditulis dalam dua bahasa (Inggris dan Indonesia) dan sedapat mungkin tidak berisikan rumus atau referensi. Abstrak harus meringkas tujuan penelitian, metode ringkas, hasil utama dan kesimpulan. Ditulis dalam 1 paragraf dan panjang abstrak maksimum adalah 200 kata. Times New Roman, Font size 11, Italic untuk abstrak dalam bahasa Inggris.

D. Kata kunci: terdiri dari 5 kata, Times New Roman, Font size 11.

E. Pengutipan di isi naskah menggunakan teknik rujukan berkurung (Nama, Tahun), contoh: (Wibisono, 2006).

F. Naskah hendaknya ditulis dengan sistematika yang terstruktur, konsisten, dan lugas.

1. Naskah ditulis dalam spasi 1, satu kolom, jenis font Times New Roman, 11.

2. Ukuran kertas $A 4(210 \times 297 \mathrm{~mm})$, portrait, dengan marjin kiri $3 \mathrm{~cm}$ dan kanan/atas/bawah 2,5 $\mathrm{cm}$.

3. Semua penomoran halaman di kanan bawah.

4. Jumlah halaman total dari Judul hingga Daftar Pustaka minimal 10, maksimal 15 halaman.

5. Naskah dapat ditulis dengan menggunakan bahasa Indonesia yang baik dan benar atau bahasa Inggris dengan tata bahasa (grammar) yang benar.

G. Naskah sebaiknya di sajikan dalam beberapa bagian diantaranya :

1. Pendahuluan

2. Metodologi Penelitian

3. Hasil dan Analisa

4. Kesimpulan dan Saran

5. Daftar Pustaka

H. Untuk penomoran menggunakan angka arab dan rata kiri-kanan. Contoh sbb:

1. Pendahuluan

Tulisan mulai dari paling kiri (spasi 1)

1.1 Latar Belakang Masalah

Tulisan mulai dari paling kiri (spasi 1)

1.2 Tujuan Penelitian

Tulisan mulai dari paling kiri (spasi 1)

2. Metodologi Penelitian

Tulisan mulai dari paling kiri (spasi 1)

2.1. Metode ....

Tulisan mulai dari paling kiri (spasi 1)

2.2. Dst ...

Tulisan mulai dari paling kiri (spasi 1)

3. Hasil dan Analisa

Tulisan mulai dari paling kiri (spasi 1)

4. Kesimpulan dan Saran

Tulisan mulai dari paling kiri (spasi 1)

I. Rumus. Setiap rumus diberi nomor pemunculan di sisi kanan dengan menggunakan angka arab di dalam kurung.

J. Tabel. Pada saat penulisan naskah, Tabel dipisahkan dari isi naskah, untuk memudahkan proses editing dan layout. Tabel diberi nomor menggunakan angka arab disertai keterangan (judul tabel). Nomor dan keterangan tabel diletakkan diatas. 
K. Gambar. Pada saat penulisan naskah dipisahkan dari isi naskah, untuk memudahkan proses editing dan layout. Gambar diiberi nomor dengan menggunakan angka arab disertai keterangan (judul gambar). Nomor dan keterangan gambar diletakkan di bawah dengan posisi di tengah (center).

L. Daftar Pustaka. Setiap rujukan disertai dengan keterangan yang mengacu pada daftar pustaka yang primer, muktahir dan relevan. Ditulis secara berurutan abad. Semua referensi yang digunakan ditulis pada daftar pustaka dengan contoh format sebagai berikut:

- Jurnal

Alfanura, F., Arai. T., and Putro. U.S. (2010). System Dynamics Modelling for E-Government Implementation: a Case Study in Bandung City, Indonesia. Jurnal Manajemen Teknologi 9 (2): 121-145.

- Buku

Wibisono, D. (2006). Manajemen Kinerja: Konsep, Desain dan Teknik Meningkatkan Daya saing Perusahaan. Jakarta: Penerbit Erlangga. ISBN: 9797815404.

- Tesis/Disertasi

Hermawan, P. (2009). Drama-theoretic Analysis of Dilemmas of Negotiation and its Application.[Dissertation]. Jepang: Tokyo Institute of Technology.

- Internet

Howard, N. (1995). Confrontation Analysis: How to Win Operations Other than War. CCRP Publication. Washington DC: Departement of Defence. Available at www.dodccrp.org. [accessed 20 Oktober 2011].

\section{PROSES PENYUNTINGAN OLEH MITRA BESTARI DAN PUBLIKASI}

Naskah sebelum diberikan ke mitra bestari akan ditinjau ulang oleh Tim Redaksi dengan melakukan blind review. Apabila masih ditemukan kesalahan dalam format penulisan Naskah maupun kelengkapan data, Tim Redaksi akan meminta penulis untuk memperbaikinya. Selanjutnya, Naskah akan dinilai dan dievaluasi mitra bestari secara semu ganda (double blind). Naskah akan ditinjau dan dievaluasi oleh dua atau lebih mitra bestari berkenaan dengan kompetensinya terhadap Naskah yang telah dikirimkan.

Mitra bestari menentukan Naskah yang dikirim layak atau tidak untuk dipublikasikan.

Adapun keputusan yang diambil oleh mitra bestari terkait yaitu, diterima, revisi, dan ditolak.

Keputusan yang ditetapkan oleh mitra bestari adalah final.

Hasil penilaian dari mitra bestari akan dikirim melalui e-mail untuk direvisi oleh penulis dan akan diperiksa kembali hasil revisi penulis oleh mitra bestari. Selanjutnya, ketika sudah disepakati maka Naskah siap untuk dipublikasikan.

Penulis akan menerima informasi dari Tim Redaksi mengenai Naskah yang telah dikirim. Hasil final yang diterima untuk dipublikasikan di KILAT akan dikirim masing-masing 2 (dua) eksemplar dan diberikan fee penulis ke alamat dan rekening Penulis yang bersangkutan. Tim Redaksi sangat berterima kasih dan mengharapkan kontribusi dari Penulis untuk penerbitan berikutnya.

\section{TERIMA KASIH}

